\title{
artigo
}

Nogueira, I.B.G.; Nóbrega, C.M.M.; Júnior, J.N.A.F.; Matos Neto, L.A.V.D.B.; Norões, M.E.A.T.; Cavalvanti, F.F.;

O uso do whey protein no processo de formação óssea pós-fratura

\section{O uso do whey protein no processo de formação óssea pós-fratura}

The use of whey protein in the post-fracture bone formation process

El uso de proteína de suero en el proceso de formación ósea postfractura

\section{RESUMO}

O leite apresenta uma das suas proteínas o Whey, que apresenta vários componentes em sua composição que trazem benefícios para formação óssea, por meio de supressão dos osteoclastos e estimular os osteoblastos. Tendo como objetivo do artigo, expor de maneira clara e sucinta, a importância do Whey como adjuvante no processo de consolidação óssea. Metodo: Realizou-se uma revisão bibliográfica sobre o tema em banco de dados da PubMed e Biblioteca Virtual de Saúde (BVS) com uso de alguns descritores e critérios de inclusão para seleção dos Artigos. Resultados: Estudos demonstraram a capacidade do Whey em criar um ambiente anabólico para o tecido ósseo, por estimular fatores que foram o osso e anular fatores de absorção óssea. Conclusão: Com isso, por todos fatores apresentados nos resultados, tal substância é eficaz na consolidação óssea.

DESCRITORES: Proteínas do soro do leite; Osteoblasto.

\section{ABSTRACT}

Milk has one of its proteins, Whey, which has several components in its composition that bring benefits to bone formation, by suppressing osteoclasts and stimulating osteoblasts. Having as objective of the article to expose in a clear and succinct way, the importance of Whey as an adjuvant in the bone healing process. Methodo: A bibliographic review was carried out in a PubMed and Biblioteca Virtual de Saúde (BVS) database, using some descriptors and inclusion criteria for selecting articles. Results: Studies have demonstrated the ability of Whey to create an anabolic environment for bone tissue, by stimulating factors that were bone and canceling factors of bone absorption. Conclusion: With that, for all factors presented in the results, this substance is effective in bone healing.

DESCRIPTORS: Whey protein; Osteoblast.

\section{RESUMEN}

La leche tiene una de sus proteínas, el suero de leche, que tiene varios componentes en su composición que aportan beneficios a la formación ósea, al suprimir los osteoclastos y estimular los osteoblastos. Teniendo como objetivo el artículo exponer de forma clara y sucinta, la importancia del Whey como coadyuvante en el proceso de cicatrización ósea. Metodo: Se realizó una revisión bibliográfica sobre el tema en una base de datos PubMed y Biblioteca Virtual de Saúde (BVS), utilizando algunos descriptores y criterios de inclusión para la selección de artículos. Resultados: Los estudios han demostrado la capacidad de Whey para crear un ambiente anabólico para el tejido óseo, estimulando factores que eran los huesos y cancelando los factores de absorción ósea. Conclusión: Con eso, para todos los factores presentados en los resultados, esta sustancia es efectiva en la curación ósea.

DESCRIPTORES: Proteínas de suero; Osteoblasto.

RECEBIDO EM: 27/11/2020 APROVADO EM: 24/12/2020

\section{Isaac Breno Gomes Nogueira}

Graduando em Medicina na Faculdade Ciências Médicas da Paraíba, Cabedelo - PB.

ORCID: 0000-0001-7001-473X

\section{Cynthia Maria Moreira da Nóbrega}

Graduanda em Medicina na Faculdade Ciências Médicas da Paraíba, Cabedelo - PB.

ORCID: 0000-0002-9203-734X 


\section{José Nadilson Azevedo Ferreira Júnior}

Graduando em Medicina na Faculdade Ciências Médicas da Paraíba, Cabedelo - PB.

ORCID: 0000-0002-8233-9088

\section{Luiz Alberto Van den Brule Matos Neto}

Graduando em Medicina na Faculdade Ciências Médicas da Paraíba, Cabedelo - PB.

ORCID: 0000-0002-2450-2510

\section{Maria Eduarda de Alencar Tavares Norões}

Graduanda de Medicina na Faculdade de Ciências Médicas da Paraíba, Cabedelo - PB.

ORCID: 0000-0001-6353-4964

\section{Felipe Faustino Cavalvanti}

Graduando de Medicina na Faculdade Ciências Médicas da Paraíba, Cabedelo - PB.

ORCID: 0000-0002-1502-8335

\section{INTRODUÇÃO}

0 leite é uma fonte barata de compostos necessários para o desenvolvimento e regeneração óssea, contendo duas principais fontes de proteína: a caseína e as proteínas do soro do leite (whey); ${ }^{1}$ sendo assim, é possível relatar que o whey protein é mais eficaz do que a caseína nas condições da sua capacidade de digestão mais rápida, visto que, a taxa de hidrólise é mais lenta e a cinética possui uma melhor absorção quando ligada a presença de componentes bioativos. ${ }^{2}$

O whey protein é considerado uma proteína completa, visto que os seus componentes são $\beta$-lactoglobulina, $\alpha$-lactoalbumina, albumina de soro bovino, imunoglobulinas, lactoferrina, lactoperoxidase, glicomacropeptídeo; onde possuem múltiplas ações biológicas e vantagens para melhoria da saúde, como também para o tratamento de patologias, prevenção do câncer, combate aos microbianos, agentes mutagênicos; e é responsável pelo incremento do nível de glutationa, incremento da resposta de saciedade, realce da atividade da esterase pré-gástrica e serve também para a regulação do fósforo. ${ }^{2}$

Foi também comprovado que o whey protein suprime a reabsorção óssea mediada por osteoblastos e a formação de osteoclastos, usando assim o osteoclasto pré-existente e recém formado e o sistema de células hematopoiéticas. ${ }^{2}$ Tendo isso em vista, é importante saber que os osteoblastos se originam em um método que engloba células multipotente mesenquimais que procriam e sofrem uma diferenciação sequencial dos progenitores em osteoblastos proliferantes, osteoblastos produtores de matriz óssea, e finalmente osteócito (células ósseas). O progresso e a maturação dos osteoblastos requerem vários fatores indutores, incluindo a proteína morfogenética óssea (BMPs) e o fator de crescimento semelhante à insulina I (IGFI). ${ }^{3}$

Há estudos que mostram que a proteína isolada do leite aumenta a proliferação celular osteogênica e a sua diferenciação, ${ }^{2}$ auxiliando também no processo de consolidação óssea, no qual, ocorre em três fases intimamente integradas e sequenciais: 1 ) inflamatória, durante a qual o tecido necrótico é removido; 2) reparatória, quando a rápida síntese de nova matriz ocorre; e 3) remodelação, na qual a desorganizada matriz da fase de reparo sofre processo de maturação, transformando-se em estrutura compacta e funcionalmente eficiente. ${ }^{4}$

Em paralelo a isso, ocorrem lesões vasculares, que promovem hemorragia variável, além de proporcionar a formação de hematoma que envolve o foco de fratura, faz que os segmentos lesados fiquem, em suas extremidades, desprovidos de nutrição e evoluem para necrose. O hematoma é organizado, com afluxo de polimorfonucleares e células pluripotenciais, fazendo com que o tecido fibrovascular do coágulo seja substituído por fibras de colágeno. Seguem-se a reabsorção do tecido necrótico e a proliferação e diferenciação das células osteogenitoras, no periósteo, no endósteo e na medula óssea em fibroblastos e condroblastos e ou osteoblastos. ${ }^{4}$

Isto é, a proteína do soro de leite - whey protein - é formado por um grupo de proteínas básicas do soro do leite e é também eficaz na prevenção da perda óssea, estimulando a deposição óssea (formação óssea) e suprimindo a retirada (reabsorção óssea); ${ }^{5}$ tal proteína, também está sendo utilizada por indivíduos de forma abundante como um suplemento dietético ${ }^{2}$, pois há um equilíbrio entre a reabsorção óssea por osteoclastos e formação por osteoblastos que sustenta a homeostase óssea por meio de um processo denominado remodelação óssea. ${ }^{3}$ Portanto, pode-se concluir que o whey protein torna-se eficaz na diminuição de ocorrências de doenças associadas aos ossos, incluindo a osteoporose. ${ }^{2}$

Objetivou-se expor de maneira clara e sucinta, a importância do Whey Protein como adjuvante no processo de consolidação óssea, além disso, relatar seus benefícios à população em geral.

\section{MÉTODO}

Este material constitui um estudo de revisão sistemática da literatura, no qual se propõe em analisar produções científicas com tema em comum com o objetivo de reunir as informações centrais das mesmas em um único local e facilitar a explicitação do uso do whey protein como cofator na osteogênese. A confecção dessa obra seguiu a seguinte ordem: pergunta 
norteadora, coleta de dados, avaliação dos dados, análise das publicações e discussão dos resultados.

A primeira fase, pergunta norteadora do trabalho, foi: "o uso do suplemento proteico a bases do soro do leite tem importância no desenvolvimento ósseo de forma mais efetiva? ". E, a partir desse questionamento, foi possível dar continuidade às fases seguintes. Nesse âmbito, a coleta de dados, segunda fase, foi feita dentro da Biblioteca Virtual de Saúde (BVS), e PUBMED, durante o dia $19 / 11 / 2020$ ao dia $05 / 12 / 2020$, tendo como ponto de partida a análise dos DeCSDescritores em Ciência de Saúde, na busca rápida, para verificar a existência das seguintes sequências lógicas: proteínas do soro do leite and osteoblast. Tendo em vista a existência desses termos, deu-se continuidade à procura do material fazendo o uso da opção busca avançada. Nela, foram inseridos os descritores analisados associados a operadores booleanos de soma. Sendo assim, pesquisou-se: whey protein AND osteoblast. Foram encontrados 96 documentos. Dessa forma, para refinar a especificidade do acervo obtido, houve a utilização dos seguintes critérios de exclusão para filtrar esse grupo de arquivos: texto completo disponível, ano de publicação (2011 a 2020) e idioma: portugues, inglês e espanhol. Após essa ação, restaram 53 artigos.

$\mathrm{Na}$ terceira fase, momento de avaliar os dados, após a leitura na íntegra das produções obtidas foi possível aplicar o critério de exclusão para: dados que não condizem com o tema proposto por apresentarem explicitações sobre o uso do whey em outras espécies, textos que possuíam duplicidade de suas réplicas e trabalhos que não apresentavam o idioma selecionado, restando,

Quadro 1: Apresentação do local de ação do whey protein e o respectivo benefício apresentado para a aceleração do processo de consolidação óssea. ${ }^{6}$

\begin{tabular}{|l|l|}
\hline INTERAÇÃO DO WHEY & \multicolumn{1}{|c|}{ BENEFícIO } \\
\hline Ação sobre Osteoblastos & $\begin{array}{l}\text { Aumento da proliferação e diferenciação os osteoblastos, } \\
\text { aumenta a deposição de cálcio e diminui a reabsorção óssea }\end{array}$ \\
\hline Ação na Fosfatase Alcalina & Aumenta a mineralização nos osteoblastos \\
\hline Ação sobre Osteoclastos & Diminui a proliferação \\
\hline
\end{tabular}

assim, 6 artigos. Esses foram selecionados pelo critério de inclusão por possuírem média e alta relevância para esse trabalho.

Em sequência, a quarta fase foi o momento utilizado para avaliar as publicações disponíveis a fim de certificar que as mesmas continham todos os critérios selecionados e a qualidade esperada. Aqui, houve sucesso de $100 \%$ e iniciou-se o estudo afinco das 6 publicações encontradas, realizando a extração de dados dos artigos de forma independente. A quinta e última fase, discussão dos resultados, foi o espaço propício para descrever a importância em evidenciar o uso de whey protein como fator de osteogênese, um tema de interesse global, que interessa a todos os seres humanos, tendo em vista o fato de que a população em geral necessita de um crescimento ósseo saudável. fator de osteogênese, um tema de interesse global, que interessa a todos os seres

humanos, tendo em vista o fato de que a população em geral necessita de um crescimento ósseo saudável.

\section{RESULTADOS E DISCUSSÕES}

Muitos estudos têm demonstrado os benefícios do soro do leite bovino no metabolismo ósseo, tanto in vitro como in vivo. Esses estudos mostraram que o whey e seus derivados apresentaram o potencial de estimular a proliferação e a diferenciação do osteoblasto MC3T3E1, quanto ao aumento do teor de proteínas e hidroxiprolina, essa maturação sendo induzida por fatores como a proteína morfogenética óssea (BMPs) e pelo fator de crescimento semelhante à insulina tipo 1 (IGF1). Além disso, o whey ainda demonstrou suprimir a reabsorção óssea mediada pelo osteoclasto. ${ }^{1}$

Outro benefício apresentado pelo whey, foi o aumento da atividade da fosfatase alcalina em implantes ósseos desmineralizados, indicando efeito positivo na formação do osso. ${ }^{2}$ Entretanto, a ação mais evidenciada do soro do leite no reparo ósseo é a ação sobre os osteoblastos MC3T3E1, aumentando a proliferação desses osteoblastos, sendo um processo dependente da concentração, foi utilizado o whey a 62,5 a $500 \mu \mathrm{g} / \mathrm{mL}$. Tendo também aumento da ação da fosfatase alcalina (ALP) nessas células, a ação da ALP nos osteoblastos é essencial para a minerali- 
zação, nesse caso foi utilizado o whey na concentração de 250 a $500 \mu \mathrm{g} / \mathrm{mL}$. Ademais há o aumento da deposição de cálcio nas células MC3T3E1, que é um mineral essencial para a formação óssea. ${ }^{6,7}$

Em outro estudo realizado em camundongos, a lactoferrina - glicoproteína encontrada no soro do leite - apresentou melhora na densidade mineral óssea por estímulo do crescimento de osteoblastos e por inibição de células pré-osteoclásticas in vitro. ${ }^{8}$ Além disso, demonstrou uma capacidade de atuar como fator de crescimento e apresentou ser um agente anabólico para o tecido ósseo, tanto in vitro como in vivo. ${ }^{9}$ Outra pesquisa realizada, buscou mensurar o aumento da densidade mineral óssea em crianças, mostrando um aumento de $5 \%$ em todo o corpo, dimi- nuindo em aproximadamente $9 \%$ as chances de ocorrer fratura na infância. ${ }^{10}$

Desse modo, observa-se que whey protein tem diversos benefícios para o corpo humano, além da sua ação no tecido ósseo, apresenta também aumento no nível do antioxidante glutationa,ajuda na prevenção de cânceres, possui atividade antibacteriana e aumento da imunidade passiva. ${ }^{6}$

\section{CONCLUSÃO}

Portanto, na tentativa de entender melhor como a utilização do whey seria benéfica para pacientes em situação de recuperação após uma fratura, chegou-se à conclusão de que o soro do leite, por ser considerado uma proteína completa, têm muitas vantagens para melhoria de saúde, prevenção e tra- tamento de doenças. A sua principal ação constatada para uma melhor e mais rápida consolidação óssea foi pela supressão da reabsorção óssea pelos osteoblastos e supressão da formação de osteoclastos. Esses estudos, realizados in vitro e in vivo, mostraram que há também um estímulo da proliferação e diferenciação dos osteoblastos MC3T3E1, induzido por BMPs e IGF1. Logo, pode-se considerar a utilização do whey protein, para melhorar a eficiência dos osteoblastos no período pós-fratura.

Entretanto, devem ser feitas mais pesquisas a respeito do assunto, considerando diferentes perfis de pacientes, em um viés comparativo, considerando a eficácia dessa alternativa em pacientes de diferentes idades, sexo, quanto ao mecanismo e enrgia do trauma.

\section{REFERÊNCIAS}

1. Douglas TEL, Vandrovcová M, Kročilová N, Keppler JK, Zárubová J, Skirtach AG, Bačáková L, et al.Application of whey protein isolate in bone regeneration: Effects on growth and osteogenic differentiation of bone-forming cells. Journal of Dairy Science [Internet]. 2018 jan [cited 2020 Dec 7];101(1):28-36. DOI https:// doi.org/10.3168/jds.2017-13119. Available from: https:/www. sciencedirect.com/science/article/pii/S0022030217309979\#.

2. Pandey M, Kapila R, Kapila S. Osteoanabolic activity of whey-derived anti-oxidative (MHIRL and YVEEL) and angiotensin-converting enzyme inhibitory (YLLF, ALPMHIR, IPA and WLAHK) bioactive peptides. Peptides [Internet]. 2018 jan [cited 2020 Dec 7];99:1-7. DOI https://doi.org/10.1016/j.peptides.2017.11.004. Available from: https://www.sciencedirect. com/science/article/abs/pii/S0196978117303352?via\%3Dihub.

3. Tsuji-Naito K, Jack RW. Concentrated bovine milk whey active proteins facilitate osteogenesis through activation of the JNKATF4 pathway. Bioscience, Biotechnology, and Biochemistry [Internet]. 2012 Jun 07 [cited 2020 Dec 7];76(6):1150-1154. DOI 10.1271/bbb.110990. Available from: https://www.tandfonline. com/doi/abs/10.1271/bbb.110990.

4. Junqueira LC, Carneiro J. Histologia Básica: Texto e Atlas. 13th ed. Rio de Janeiro: EDITORA GUANABARA KOOGAN LTDA; 2018. 1832 p. ISBN: 978-85-277-3216-1.

5. Rabe R, Hempel U, Martocq L, Keppler Jk, Aveyard J, Douglas TEL. Dairy-Inspired Coatings for Bone Implants from Whey Protein Isolate-Derived Self-Assembled Fibrils. International Journal of Molecular Sciences [Internet]. 2020 Aug 03 [cited 2020 Dec 7];21(15) DOI 10.3390/ijms21155544. Available from: https:// www.ncbi.nlm.nih.gov/pmc/articles/PMC7432503/.

6. Jo K, Hong KB, Suh HJ. Effects of the Whey Protein Hydroly- sates of Various Protein Enzymes on the Proliferation and Differentiation of 3T3-E1 Osteoblasts. Preventive Nutrition and Food Science [Internet]. 2020 Mar 31 [cited 2020 Dec 7];25(1):71-77. DOI 10.3746/pnf.2020.25.1.71. Available from: https://www. ncbi.nlm.nih.gov/pmc/articles/PMC7143006/.

7. Shi P, Fan F, Chen $H, X u Z$, Cheng S, Lu W, et al. A bovine lactoferrin-derived peptide induced osteogenesis via regulation of osteoblast proliferation and differentiation. Journal of Dairy Science [Internet]. 2020 Mar 20 [cited 2020 Dec 7];103(5):39503960. DOI https://doi.org/10.3168/jds.2019-17425. Available from: https://www.journalofdairyscience.org/article/S00220302(20)30207-1/fulltext.

8. Fan F, Tu M, Liu M, Shi P, Wang Y, Wu D, et al. Isolation and Characterization of Lactoferrin Peptides with Stimulatory Effect on Osteoblast Proliferation. Journal of Agricultural and Food Chemistry [Internet]. 2017 Jul 21 [cited 2020 Dec 7];65(33):71797185. DOI 10.1021/acs.jafc.7b02067. Available from: https:// pubs.acs.org/doi/abs/10.1021/acs.jafc.7b02067

9. Zhang W, Guo $H$, Jing $H$, Li Y, Wang $X$, Zhang $H$, et al. Lactoferrin Stimulates Osteoblast Differentiation Through PKA and p38 Pathways Independent of Lactoferrin's Receptor LRP1. Journal of Bone and Mineral Research [Internet]. 2013 Nov 17 [cited 2020 Dec 7];29(5):1232-1243. DOI 10.1002/jbmr.2116. Available from: https://asbmr.onlinelibrary.wiley.com/doi/full/10.1002/ jbmr.2116

10. Li Q, Zhao J, Hu W, Wang J, Yu T, Dai Y. Effects of Recombinant Human Lactoferrin on Osteoblast Growth and Bone Status in Piglets. Animal Biotechnology [Internet]. 2017 May 11 [cited 2020 Dec 7];29(2):90-99. DOI 10.1080/10495398.2017.1313269. Available from: https://www.tandfonline.com/doi/full/10.1080/ 10495398.2017.1313269?scroll=top\&needAccess=true 